\title{
Comparison of the effect of using cellulase, microwave and ultra-sonication on crude polysaccharides extraction from Vietnamese Lingzhi (Ganoderma lucidum)
}

\author{
Dam Sao Mai*, Truong Thi Thuy An, Tu Thai Binh, Nguyen Dac Anh \\ Institute of Biotechnology and Food Technology, Industrial University of Ho Chi Minh City, Ho Chi Minh City, Vietnam
}

Email address:

damsaomai@gmail.com (D. S. Mai)

To cite this article:

Truong Thi Thuy An, Tu Thai Binh, Nguyen Dac Anh, Dam Sao Mai. Comparison of the Effect of Using Cellulase, Microwave and UltraSoniccation on Crude Polysaccharides Extraction from Vietnamese Lingzhi (Ganoderma Lucidum). Journal of Food and Nutrition Sciences. Special Issue: Food Processing and Food Quality. Vol. 3, No. 1-2, 2015, pp. 49-53. doi: 10.11648/j.jfns.s.2015030102.19

\begin{abstract}
Ganoderma lucidum known as Reishi in Japanese and Lingzhi in Chinese, are commonly used in Vietnam with excellent beneficial health effects. Polysaccharides are usually considered as their main active components. To date, a careful comparison of crude polysaccharides extraction methods from the Ganoderma lucidum, which is grown in Vietnam, has not been performed. In this study, the crude polysaccharides from fruiting bodies of Vietnamese Lingzhi collected from the South of Vietnam were analyzed and compared based on monitoring the absorbance of the samples in $490 \mathrm{~nm}$, as well as enzymatic, microwave and ultrasonic methods with different surveyed parameters, such as: concentration of enzyme, microwave frequencies, extraction time, extraction temperature, ratio of sample and water. The results showed that the highest crude polysaccharide was extracted when using cellulase in enzymatic method.
\end{abstract}

Keywords: Ganoderma Lucidum, Polysaccharides, Enzymatic, Microwave, Ultrasonic

\section{Introduction}

Polysaccharide is one of the most important compounds in Lingzhi mushroom. There are two major kinds: GL-A: Gal:Glu:Rham: Xyl $(3,2: 2,7 ; 1,8: 1,0) \mathrm{M}=23000 \mathrm{Da}$, and GLB: Glu:Rham: Xyl $(6,8: 2,0 ; 1,0) \mathrm{M}=25000 \mathrm{Da}$. To analyzing the structure of polysaccharide the main compounds of polysaccharide are glucose (Bao et al. 2001; Wang et al. 2002), xylose, mannose, galactose, and fructose... (Lee, Lee, and Lee 1999; Bao et al. 2002)

In Lingzhi compounds there is also protein exiting. The mushroom protein consists of necessary amino acid, especially lysine and leucine. The total lipid is low in lingzhi. (Chang and Buswell 2008)

The aim of this study is extracted polysaccharide from lingzhi in different methods, such as: boiling water, enzymatic, microwave and ultrasonic methods. Then find the suitable method for polysaccharide extraction.

\section{Materials and Methods}

Materials: Lingzhi was collected from $\mathrm{Cu}$ Chi farm Survey the optimized polysaccharide extraction:
- Survey the polysaccharide extraction with different rate of water $(1: 20,1: 30,1: 40,1: 50,1: 60)$, in boiling water, in different extraction time $(10,20,30,40,50,60,70$ $\min )$.

- Survey the polysaccharide extraction with microwave method with different microwave power $(115,345,575$, $920,1150 \mathrm{~W})$, in different extraction time $(8,9,10,11$, $12 \mathrm{~min})$.

- Survey the polysaccharide extraction with ultrasonic method with different extraction temperature $(40,50$, $\left.60,70,80^{\circ} \mathrm{C}\right)$, in different extraction time $(6,9,12,15$, $18 \mathrm{~min})$.

- Survey the polysaccharide extraction with enzymatic method with different extraction temperature $(35,40$, $\left.45,50,55^{\circ} \mathrm{C}\right)$, different enzyme concentration $(0,0.4$, $0.5,0.6,0.7,0.8 \mathrm{~mL})$, in different extraction time $(1.0$, $2.5,4.0,5.5,7.0 \mathrm{hrs})$.

Spectrophotometer analysis: Color changes of the treated samples were measured at $490 \mathrm{~nm}$ with a UV/Vis spectrophotometer (Harivaindaran, Robecca, Chandran, 2008).

Statistical analysis: All measurements were done in triplicate. Using Modde 5 software to perform optimization. 
Analyses of Variance (ANOVA) were conducted by using SPSS Version 13.0 for Windows (SPSS). Turkey tests were performed to test the significant differences between the mean values for treatments $(\mathrm{p}<0.05)$

\section{Results and Discussion}

\subsection{Survey the Polysaccharide Extraction with Different Rate of Water}

The water was chosen for polysaccharides extraction, this solvent was chosen in some scientists, who was investigated that water is more suitable for polysaccharide extraction from Lingzhi than other solvent like ethanol, chloroform (Nguyen Thi Minh Tu, 2009).

When the ratio between material and solvent was raised from 1:20 to 1:50, the amount of extracted polysaccharide was also raised till the ratio reached to $1: 60$. The ratio of solvent and raw material was 1:50 gave the best result for extraction with $2.14 \%$ of efficiency (Fig.1a). This can be explained when the water and material keep balance at the ratio of 1:50, at this point the water activity effects much on the diffusion of substances within the cells to out.

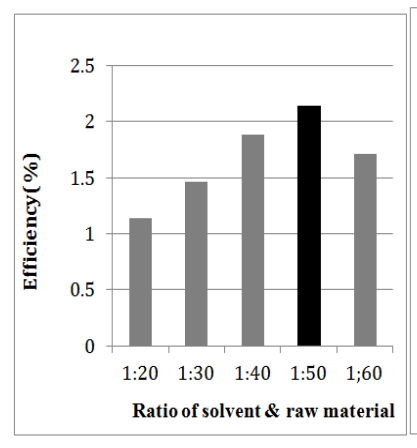

a

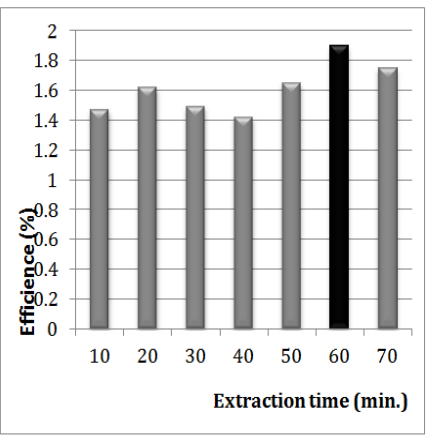

$\mathrm{b}$
Fig. 1. The factor that effect on the polysaccharide extraction at boiling temperature. a. Effect of the ratio of material and water, $b$. Effect of the extraction time.

At the boiling temperature the best extraction time was 60 min, which gave the efficiency at $1.90 \%$. The extraction efficiency in the boiling water was higher then in the ethanol $96^{\circ}$ at this solvent boiling temperature. (Nguyen Tuan Anh et.al, 2007)

When the extraction time is increasing from 10 to $60 \mathrm{~min}$., the polysaccharide extraction efficiency rose from $1.42 \%$ to $1.9 \%$, but after $60 \mathrm{~min}$. their efficiency was decreased (Fig.1b). When the extraction time increasing, more lingzhi components begin to be extracted, but after the optimal time, when most components were extracted, it was not signification when the extraction time continue to rise.

\subsection{Survey the Polysaccharide Extraction with Enzymatic Method}

The enzymatic method gave the best result when cellulose was used with $0.6 \mathrm{~mL}(\sim 0.24 \%)$ of concentration, at $50^{\circ} \mathrm{C}$ in $2.5 \mathrm{hrs}$ (Fig.2). In this condition, the amount of polysaccharide was $4.37 \%$.

When rising the treatment time from $1 \mathrm{hrs}$ to $4 \mathrm{hrs}$, the efficiency also raised. But when the treatment time was over than $4 \mathrm{hrs}$, the amount of extracted polysaccharide reduced. The results showed that after 4 hrs the highest amount was extracted, but there was not signification different comparing with receiving amount of extracted polysaccharide after $2.5 \mathrm{hrs}$. So the chosen time for treatment was $2.5 \mathrm{hrs}$

If the extraction temperature were increased, the using enzyme would be inactive. That's why although the efficiency of the polysaccharide extraction was higher when the extraction temperature was rising, but in the enzymatic method, the temperature is only raising until the enzyme is still active.

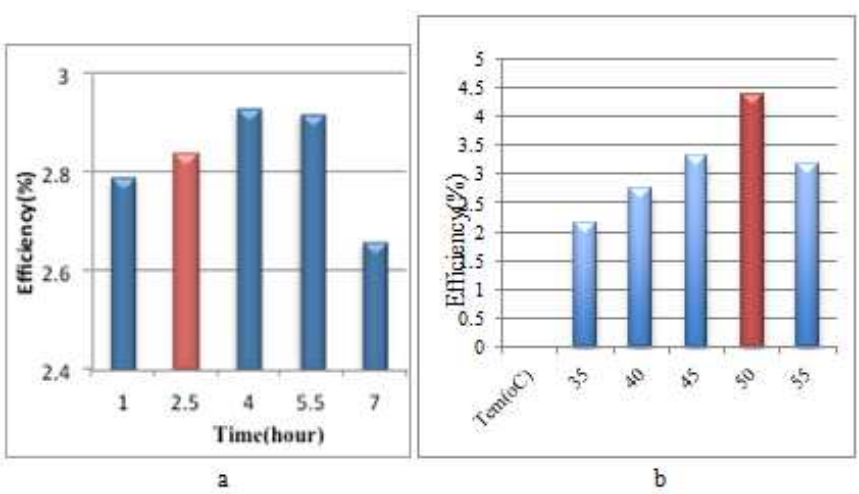

Fig. 2. The factor that effect on the polysaccharide extraction at the enzymatic method. a. Effect the extraction time, b. Effect of the extraction temperature.

\subsection{Survey the Polysaccharide Extraction with Microwave Method}

When the power of the microwave is increasing from 115 to $1150 \mathrm{~W}$, the polysaccharide extraction efficiency raised from $1.34 \%$ to $1.9 \%$, but non-significant difference was observed in statistics analysis, but have differences between other samples (Fig.3a).

Under the influence of an electric field, the dipole molecules tend to arrange along the electric field direction. Hence the alternating electric field at very high frequencies $(\mathrm{MHz})$ will cause disturbance velocity friction between the molecules are very large, which is the source of the material warming.

The more polar compounds more rapidly heated under microwave irradiation. There is microwave activation of polar molecules, especially water. Water heated by microwave absorption and evaporation, creating high pressure at work, making the water move from the center to the surface material. Microwave also works to enhance mixing; makes increased exposure phase response performance is greater. So powerful extracts significantly help more

When rising the treatment time with microwave from 8 min. to $10 \mathrm{~min}$, the efficiency also raised from $2.2 \%$ to $2.8 \%$ (Fig.3b). But when the microwave treated time was over than $11 \mathrm{~min}$, the amount of extracted polysaccharide reduced to 
$2.22 \%$. The results showed that after 9 or 10 min the highest amount was extracted, but there was not signification. So the chosen time for treatment was 9 min.

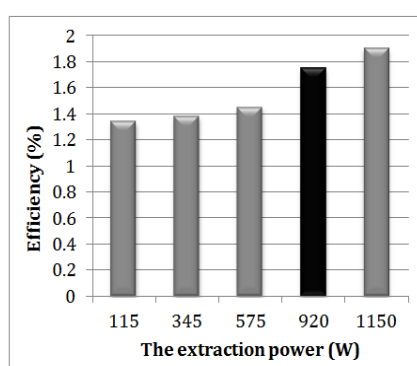

a.

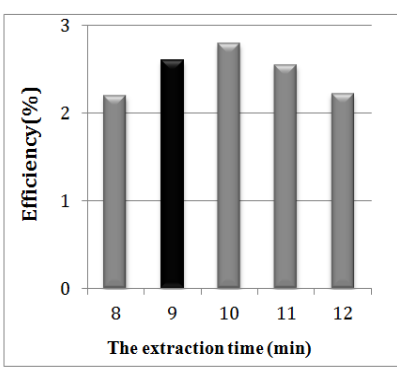

b.
Fig. 3. The factor that effect on the polysaccharide extraction at the microwave method. a. Effect of power of microwave, b. Effect of the extraction time.

\subsection{Survey the Polysaccharide Extraction with Ultrasonic Method}

When rising the extracted temperature time in ultrasonic method from 40 to $80^{\circ} \mathrm{C}$, the efficiency also raised from $1.37 \%$ to $1.66 \%$ at $80^{\circ} \mathrm{C}$ (Fig. $4 \mathrm{a}$ ). The results showed that after 9 or $10 \mathrm{~min}$ the highest amount was extracted, but there is not signification. So the chosen time for treatment was $9 \mathrm{~min}$.

Ultrasound effect on the increasing of the solute solubility in the solvent and increases the solute diffusion process. The high-intensity ultrasound waves can also break out the cell structure to accelerate the process of the extraction. In ultrasonic method, the mixture extraction with polar solvents will be heated up. However, it is also possible to heat the extraction process to be faster. Therefore, high temperature $\left(80^{\circ} \mathrm{C}\right)$ promoted the polysaccharide extraction to occur most strongly. a.

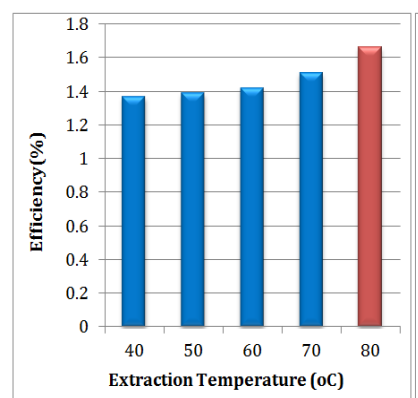

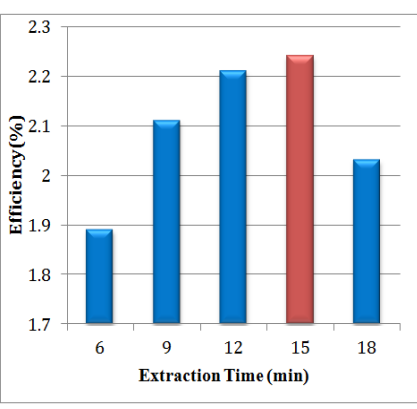

b.
Fig. 4. The factor that effect on the polysaccharide extraction at the ultrasonic method. a. Effect of the extraction temperature, $b$. Effect of the extraction time.

When rising the treatment time from $6 \mathrm{~min}$. to $15 \mathrm{~min}$, the efficiency also raised from $1.89 \%$ to $2.24 \%$ (Fig.4b). But when the ultrasonic treated time is over than $15 \mathrm{~min}$, the amount of extracted polysaccharide reduced. The results showed that after 15 min the highest amount was extracted, there was signification with other samples. So the chosen time for treatment was $15 \mathrm{~min}$.

Table 1. Compare the effect of using cellulase, microwave and ultrasonic on crude polysaccharides extraction from Vietnamese Lingzhi

\begin{tabular}{|c|c|c|c|c|}
\hline Extraction method & Boiling water & Enzymatic method & Microwave method & Ultrasonic method \\
\hline The efficiency (\%) & $1.90 \%$ & $4.37 \%$ & $2.80 \%$ & $2.24 \%$ \\
\hline
\end{tabular}

Comparing the polysaccharide extraction methods, the enzymatic method gave the best result (Table 1), but because of enzyme addition it makes higher price for the products comparing with other methods. So depending on the condition the suitable method can be chosen. Using enzyme will be required more budget for the process, but using microwave or ultrasonic will be required more equipment.
Following the above results the enzymatic method gave the best result. That's why the optimizing of this method was surveyed.

The experiment was conducted according to a central composite design, with the following variables: enzyme concentration $(0.5-0.7 \mathrm{~mL}$, center value was $0.6 \mathrm{~mL})$ and extraction time (1-4hrs, center value was $2.5 \mathrm{hrs})$ (Table 2).

\subsection{Optimizing of the Extraction Time and the Concentration of Using Cellulase in the Enzymatic Method}

Table 2. Results of optimizing the extraction time and concentration of using cellulase effect on the extracted crude polysaccharides from Vietnamese Lingzhi fruit in the enzymatic method

\begin{tabular}{|c|c|c|c|c|c|}
\hline Samples & $\begin{array}{c}\text { Amount of Cellulase } \\
(\mathrm{mL} / 250 \mathrm{~mL})\end{array}$ & Extraction time (hrs) & $A(490 n m)$ & Extraction polysaccharide & Extracted capacity (\%) \\
\hline M1 & 0.5 & 1 & 0.459 & 145.9229532 & 2.91846 \\
\hline M2 & 0.7 & 1 & 0.502 & 160.7383757 & 3.21477 \\
\hline M3 & 0.5 & 4 & 0.462 & 146.9565874 & 2.93913 \\
\hline M4 & 0.7 & 4 & 0.488 & 155.9147498 & 3.11829 \\
\hline M5 & 0.4586 & 2.5 & 0.425 & 134.2084331 & 2.68417 \\
\hline M6 & 0.7414 & 2.5 & 0.576 & 186.2346842 & 3.72469 \\
\hline M8 & 0.6 & 4.621 & 0.478 & 152.4693027 & 3.04939 \\
\hline
\end{tabular}




\begin{tabular}{cccccc}
\hline Samples & $\begin{array}{c}\text { Amount of Cellulase } \\
(\mathbf{m L} / \mathbf{2 5 0 m L})\end{array}$ & Extraction time (hrs) & A (490nm) & Extraction polysaccharide & Extracted capacity (\%) \\
\hline M9 & 0.6 & 2.5 & 0.591 & 191.4028548 & 3.82806 \\
M10 & 0.6 & 2.5 & 0.618 & 200.7055619 & 4.01411 \\
M11 & 0.6 & 2.5 & 0.629 & 204.4955537 & 4.08991 \\
M12 & 0.6 & 0.597 & 193.4701231 & 3.8694 \\
M13 & 0.6 & 2.5 & 0.589 & 190.7137654 & 3.81428 \\
\hline
\end{tabular}

The optimal result was treated by Modde 5 (Fig.5) with $\mathrm{Q}^{2}$ $=0.629>0.5$ and $\mathrm{R}^{2}=0.933>0.8$. The results are absolutely suitable with the optimal model. The regression equation of crude polysaccharide extracted efficiency depending on the extraction time and concentration of cellulase was as following:

Investigation: toiuuhoaenzyme (MLR) Contour Plot

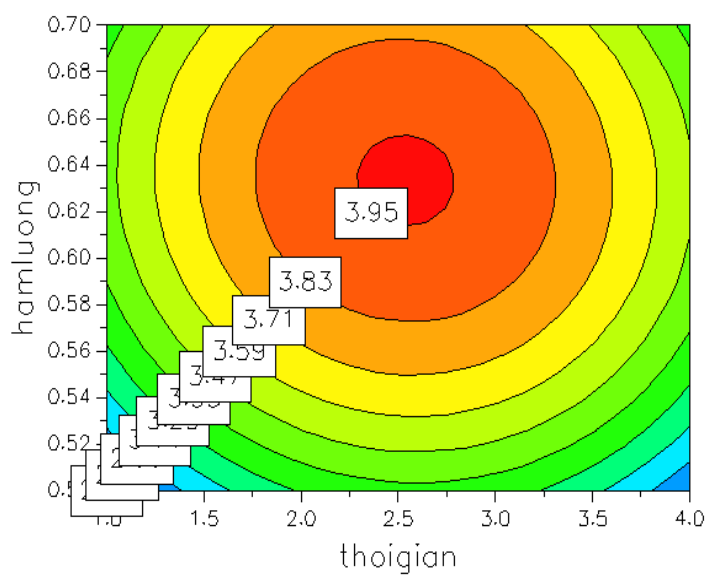

$$
\mathrm{Y}=3.923+0.243 \mathrm{X}_{1}-0.363 \mathrm{X}_{1}^{2}-0.505 \mathrm{X}_{2}^{2}
$$

( $\mathrm{X}_{1}$ is the concentration of cellulase, $\mathrm{X}_{2}$ is the extraction time)

Optimal results obtained after empirically verifiable were: the extraction time was $2.34 \mathrm{hrs}$. Concentration of using cellulase was $0.63 \mathrm{~mL}(\sim 0.252 \%)$ (Fig.5).

Investigation: toiuuhoaenzyme (MLR) Response Surface Plot

hs

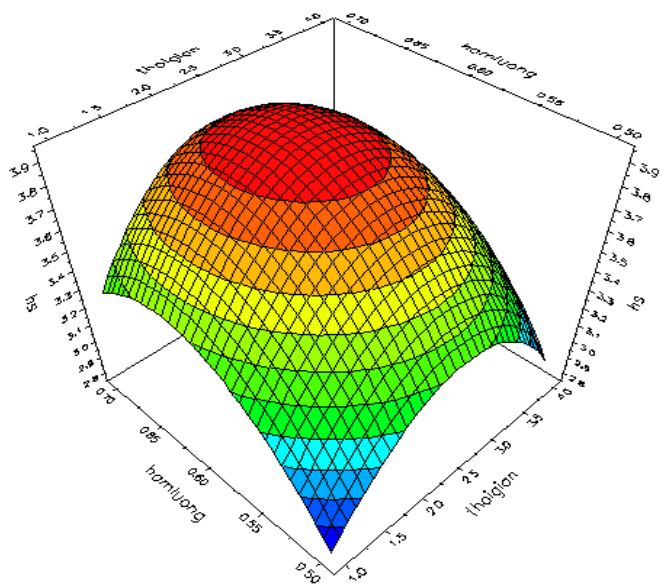

Fig. 5. Contour pilot and response surface pilot of survey the optimization of extraction time and using callulase in the enzymatic method

\subsection{Combining the Different Polysaccharide Extraction Methods}

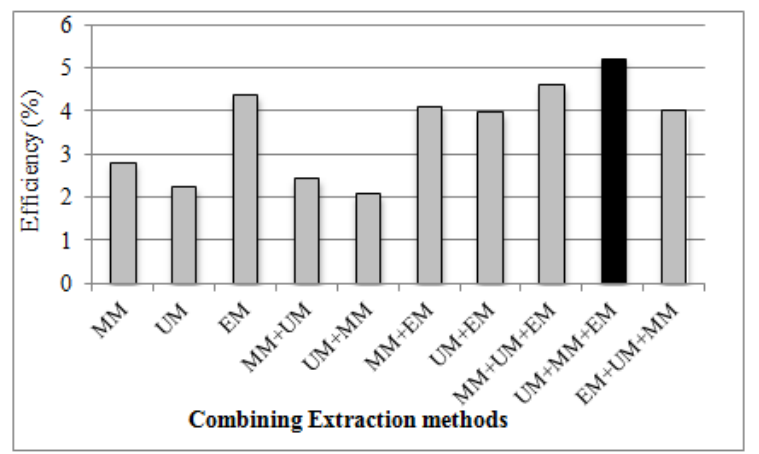

Fig. 6. The polysaccharide extraction in different combining methods

Each extraction method have different characteristic and will be suitable for different situation. To find out the best method we try to combine the different extraction method for total polysaccharide extraction from Vietnamese Lingzhi fruit. Every sample was boiling in water before using the combining methods.

The Microwave method (MM), Ultrasonic method (UM), enzymatic method (EM) was surveyed. The combining methods were combined with above methods following the order of each method, such as: Microwave and Ultrasonic method (MM+UM); Ultrasonic and Microwave method (UM+MM); Microwave and Enzymatic method (MM+EM); Microwave, Ultrasonic and Enzymatic method (MM+UM+EM); Ultrasonic, Microwave and Enzymatic method (UM + MM+ EM); Enzymatic, Ultrasonic and Microwave method $(\mathrm{EM}+\mathrm{UM}+\mathrm{MM})$. The results were shown in Figure 6.

The result showed that the combining method with Ultrasonic, Microwave and Enzymatic method (UM + MM+ EM) gave the best result (5.24\% polysaccharide extraction). The ultrasonic $(37 \mathrm{kHz})$ and microwave $(920 \mathrm{~W})$ in 9 minutes helped to pre-destroy the cell wall of the lingzhi fruit, and partly extracted the polysaccharide. After pretreatment the cellulase broke easily the cell wall and extracted the highest amount of polysaccharide (5.24\%).

\section{Conclusion}

The research showed that, the enzymatic method gave highest polysaccharide extraction from lingzhi. The percentage of polysaccharide extraction reached to $4.37 \%$ compared to dried raw material. On the other hand 
combination Ultrasonic, Microwave and Enzymatic method $(\mathrm{UM}+\mathrm{MM}+\mathrm{EM})$ gave best extraction result $(5.24 \%)$. Therefore, the suitable lingzhi polysaccharide extraction could be chosen depending on the purpose. After vacuum distillation, the products can be used to apply in food and pharmaceutical industry.

\section{References}

[1] Bao X, Liu C, Fang J, Li X. 2001. Structural and immunological studies of a major polysaccharide from spores of Ganoderma lucidum (Fr.) Karst. Carbohydr Res. 332:67-74.

[2] Wang Y. Y, Khoo K. H, Chen S. T, Lin C. C, Wong C. H, Lin C. H. 2002. Studies on the immunomodulating and antitumor activities of Ganoderma lucidum (Reishi) polysaccharides: Functional and proteomic analyses of a fucose-containing glycoprotein fraction responsible for the activities. Bioorg Med Chem..10:1057-62.
[3] Lee K. M, Lee S. Y, Lee H. Y. 1999. Bistage control of $\mathrm{pH}$ for improving exopolysaccharide production from mycelia of Ganoderma lucidum in an air-lift fermentor. J Biosci Bioeng. 88:646-50.

[4] Chang S. T, Buswell J. 2008. A. Safety, quality control and regulational aspects relating to mushroom nutriceuticals. Proc. 6th Intl. Conf. Mushroom Biology and Mushroom Products. 188-95. GAMU Gmbh, Krefeld, Germany

[5] KV Harivaindaran, OPS Rebecca, S Chandran. 2008. Study of Optimal Temperature, $\mathrm{pH}$ and Stability of Dragon Fruit (Hylocereus polyrhizus). Pakistan Journal of Biological Sciences. Vol. 11: 2259-2263

[6] Nguyen Minh Tu. 2009. The process of bioactive extraction from Lingzhi. J. Scientist and Technology, Vietnam. Vol 47 (1)

[7] Nguyen Tuan Anh, Tran Thu Huong, Nguyen Thi Phuong Ha. 2007. Survey on the conditions to extract the bioactive components from Lingzhi (Garnoderma lucidum Karst.). The proceeding of the $4^{\text {th }}$ Organics Chemistry Conference of Science and Technology in Vietnam. 